Thorax (1957), 12, 294.

\title{
VASCULAR INVASION IN BRONCHOGENIC CARCINOMA
}

\author{
BY \\ ALANDO J. BALLANTYNE, O. THERON CLAGETT, AND JOHN R. McDONALD \\ From the Sections of Surgery and Surgical Pathology, Mayo Clinic and Mayo Foundation, Rochester, \\ Minnesota, U.S.A.
}

(RECEIVED FOR PUblication AUgust 20, 1957)

Most studies dealing with routes of spread of malignant tumours have been concerned primarily with dissemination by way of the lymphatic system. This emphasis has been placed correctly, for it is primarily in dealing with lymphatic spread that any surgical or radiotherapeutic approach toward control of cancer can be successful.

It has also been recognized for a long time that malignant emboli may be disseminated by way of the blood stream. Efforts to study this route of spread have not been particularly rewarding, for any pathological examination must be limited to efforts at determining sites at which malignant cells may have reached the blood stream. Bronchogenic carcinoma has particular opportunities for widespread dissemination as a result of its ready access to the systemic circulation.

Relatively few studies have been reported on the incidence of vascular invasion in surgically resected specimens of bronchogenic carcinoma, although many observers have noted the frequency with which tumours have been found within vessels in necropsy material (Adler, 1912; Barnard and Elliott, 1930; Fried, 1927; Grove and Kramer, 1926; Simons, 1937 ; Simpson, 1929 ; Weller, 1929). In 1951 Aylwin reported a number of observations on the frequency of venous involvement in surgically resected specimens of bronchogenic carcinoma. He studied 58 resected carcinomas, using as the criterion of vascular invasion the permeation by malignant cells through all coats of the vessel at least as far as the intima. He found that $40 \%$ of the specimens showed malignant cells in contact with blood returning to the heart and that $80 \%$ of the patients whose specimens exhibited such microscopic findings died with widespread vascular deposits. $\mathrm{He}$ presented two cases in which massive malignant emboli resulted in death shortly after operation.

Indirect evidence of venous and arterial invasion has been obtained by angiocardiography in the pre-operative evaluation of patients with bronchogenic carcinoma. Complete occlusion of a pulmonary artery as seen by angiocardiography has been reported by Wiklund (1951), and distortion of arterial patterns consistent with compression or invasion has been reported in various angiocardiographic studies (Dotter, Steinberg, and Holman, 1950 ; Keil, Voelker, and Schissel, 1950 ; Slesser, Britt, and Freer, 1954).

\section{Material AND Methods}

Material for the present study consisted of lungs or lobes surgically removed for primary bronchogenic carcinoma at the Mayo Clinic from November 1950, until December, 1951. No attempt was made to select the specimens; all that could be obtained in a fresh state were included. Fifty-nine specimens were thus studied.

Macroscopic examination included a record as to the size and position of the primary tumour and the presence or absence of metastasis to the lymph nodes. A search was made in the periphery of the lung for evidence of infarction or embolic spread. The arteries and veins then were identified at the hilus and systematically opened as far as possible into the tumour. If a tumour thrombus was found in a vessel, the specimen was fixed in $10 \%$ formalin for 48 hours and sections then were taken through the desired sites. In cases in which the opened vessels did not appear to be invaded by tumour, the specimen was fixed for 48 hours and serial cuts were made through the tumour at intervals of about $4 \mathrm{~mm}$. so that the vessels traversing the tumour could be inspected. Three large blocks for sectioning were taken as a routine through the regions of tumour in which it appeared that vessels might be involved, but as many as nine blocks were taken on occasion. Serial sectioning would have given a more nearly complete picture of the manner and frequency of invasion of blood vessels, but it became apparent that, with the crude methods employed, vascular invasion was being found in a large number of cases. Sections were stained with haematoxylin and eosin; in almost all instances, the elastic-van Gieson stain also was used to show the elastic tissue of blood vessels.

\section{RESULTS}

MACroscopic Findings.-Because of the difficulty in distinguishing arteries from veins in many 
instances, no distinction was made except in those cases in which it was possible to establish unequivocally the identity of an invaded vessel. When the vessels were identified and systematically opened, it was not difficult in many specimens to find tumour thrombi either occluding a vessel or projecting into the lumen (Fig. 1).

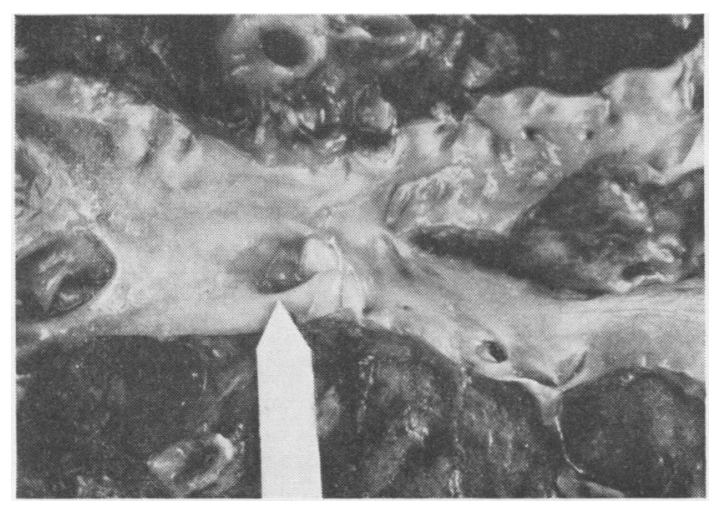

FIG. 1.-Tumour protruding into the artery to the lower lobe of the left lung.

Thrombosed vessels were seen frequently in the gross cross-sections, but it was not always possible to determine by eye if a thrombus contained tumour. Likewise, in the cross-sections in which smaller vessels were seen, it was frequently possible to pick out the arteries by their yellowish colour and wrinkled appearance. This distortion of the normally round contour apparently was produced by pressure from without the wall as well as by contraction of fibrous tissue within the lumen. Vessels were considered to be involved grossly by tumour in 28 of the 59 specimens. The spread of tumour in the vessels appeared to be largely centripetal, with growth of the tumour thrombus from smaller vessels toward the hilus.

Microscopic Findings.-In all cases microscopic proof was necessary before a case was included as showing involvement of vessels. For the purpose of this study, a vessel was considered to have been invaded so that liberation of tumour cells into the blood stream was theoretically possible if tumour cells were present within the internal elastic lamina. The elastic-van Gieson stain enabled one to distinguish the vessels readily in many cases and permitted differentiation of arteries and veins.

The malignant cells apparently had remarkable powers to infiltrate through vessel walls and frequently were found between the elastic laminae (Fig. 2a). Various degrees of thrombosis of the vessel attended this process, with subsequent organization and canalization of - the thrombus and invasion by malignant cells (Fig. $2 b$ ). In many instances, thrombosis of vessels was observed without any tumour being present in the lumen or infiltrating the walls. Proliferative intimal changes were frequent. The lumen of a blood vessel apparently did not always provide an ideal place within which tumour cells might grow, for much of the thrombus in a few instances appeared to contain necrotic tumour cells, with only the growing head of the thrombus viable.

The results obtained in reviewing the slides in these 59 cases are summarized in the table. In

TABLE

INCIDENCE OF VASCULAR INVASION BY MALIGNANT CELLS IN SURGICALLY REMOVED BRONCHOGENIC CARCINOMA IN 59 CASES

\begin{tabular}{|c|c|c|c|}
\hline \multicolumn{2}{|l|}{$\begin{array}{c}\text { Type of } \\
\text { Carcinoma }\end{array}$} & $\begin{array}{l}\text { Total } \\
\text { Cases }\end{array}$ & $\begin{array}{l}\text { Vessels Involved } \\
\text { (Caies) }\end{array}$ \\
\hline $\begin{array}{l}\text { Squamous cell .. } \\
\text { Large ", } \\
\text { Small } \\
\text { Adenocarcinoma }\end{array}$ & $\begin{array}{l}\ldots \\
\because \\
\cdots\end{array}$ & $\begin{array}{r}34 \\
10 \\
9 \\
6\end{array}$ & $\begin{array}{l}27(80 \%) \\
10(100 \%) \\
9(100 \%) \\
6(100 \%)\end{array}$ \\
\hline Total & .. & 59 & $52(88 \%)$ \\
\hline
\end{tabular}

general, the small cell carcinomas were most active in penetrating vessels and tended to involve the larger vessels. It is not possible to say whether this tendency reflects a differential rate of growth or is merely an expression of the age of the tumour. Extension into the major branches of the vessels was most prominent in tumours $5 \mathrm{~cm}$. or more in diameter (presumably those lesions that had been growing for the longest time).

Of the seven squamous cell carcinomas in which vessels were not involved, two were $4 \mathrm{~cm}$. in diameter, one measured $5 \times 3 \times 1 \mathrm{~cm}$., and the remainder were less than $2.5 \mathrm{~cm}$. in diameter. Lymph nodes contained tumour in three of these cases ; in one case, the lymph node was involved by direct extension. It was difficult to demonstrate involvement of vessels in carcinomas less than $2.5 \mathrm{~cm}$. in diameter, yet invasion of veins was demonstrated readily in one of the smallest of such lesions.

The elastic-van Gieson stain enabled us to see the elastic laminae and so to determine to our own satisfaction that arteries contained tumour fairly frequently. It was considered that arteries had been invaded by tumour in nine specimens; microscopic examination confirmed this number and added an additional instance. When the types of cells were analysed, it was found that arterial invasion was caused by squamous cell carcinoma 


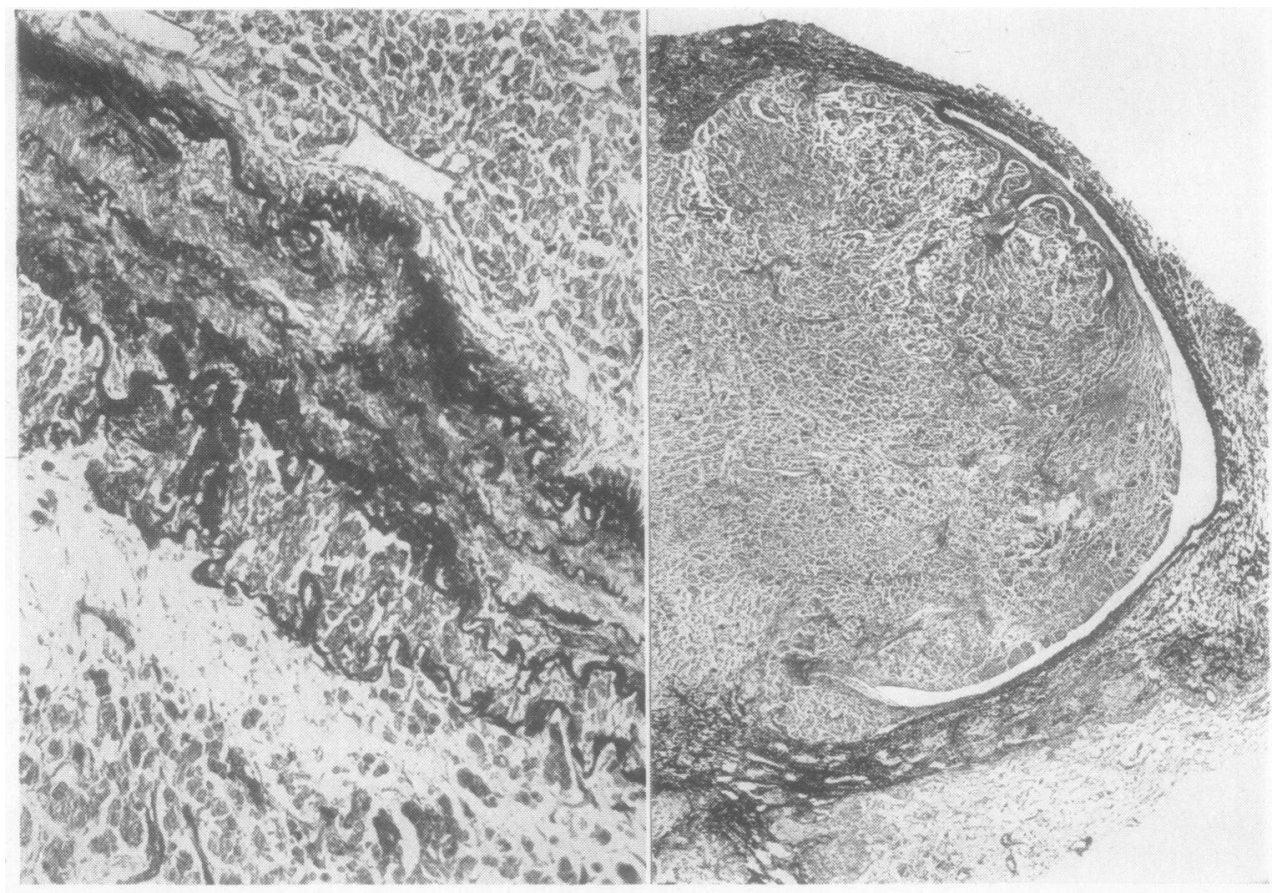

Fig. 2.-(a) Small cell bronchogenic carcinoma infiltratıng the elastic laminae of a small artery (elastic-van Gieson

135): (b) tumour thrombus protruding into a pulmonary vein (elastic-van Gieson $6 \frac{1}{2}$ ).

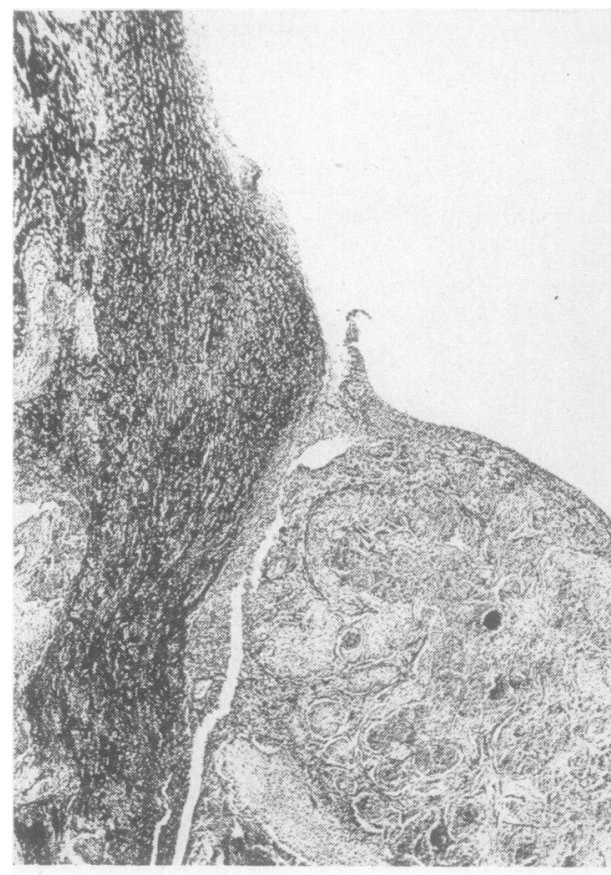

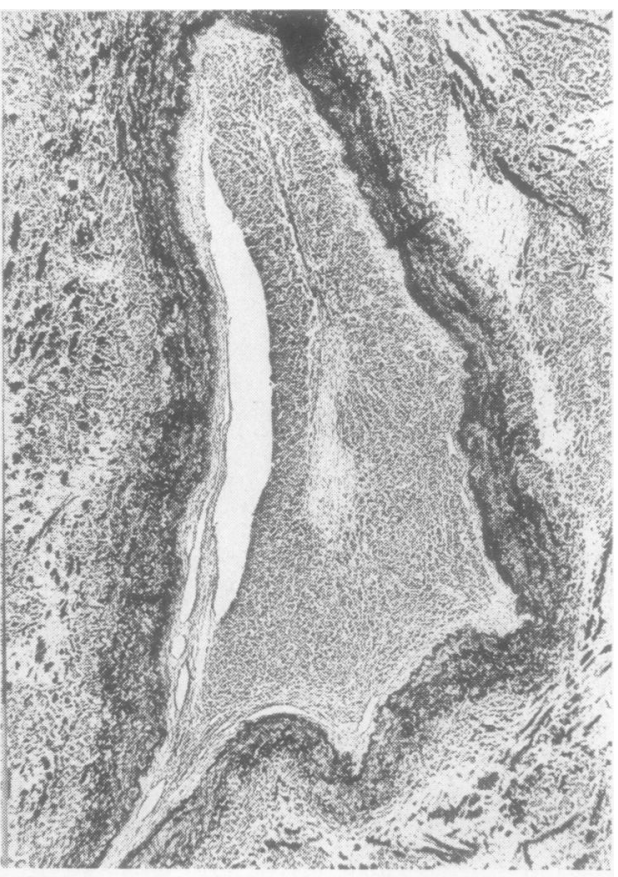

3.-(a) Section of tumour seen in Fig. 1, showing squamous cell bronchogenic carcinoma within the pulmonary artery; (b) small cell bronchogenic carcinoma growing within a small branch of the pulmonary artery (both elastic-van Gieson $\times 30$ ). 
in five cases, by adenocarcinoma in two cases, and by small cell carcinoma in three cases (Fig. 3). The largest artery invaded was the main branch to the left upper lobe, which was involved in one case. In this specimen, an adenocarcinoma $8 \mathrm{~cm}$. in diameter was present in the apical portion of the left upper lung. The tumour had extended through the pleura to involve the intercostal bundles. A tumour thrombus filled the branch of the pulmonary artery to the upper lobe and almost solidly plugged the branches to the apex; in spite of this necrosis was minimal. Multiple minute to confluent foci of adenocarcinoma occupied the apical portion of the lobe. Serial sections of the tumour were not done to determine the presence of clumps of tumour cells in arterioles and capillaries, which would have been evidence for spread through the involved artery. The whole picture strongly suggested dissemination by this means.

Relation of Symptoms to Invasion of Blood VESSELS.-It was impossible to state that invasion of blood vessels in our cases of bronchogenic carcinoma gave rise to any characteristic symptoms. No apparent correlation existed between vascular invasion within the tumour and pulmonary osteoarthropathy or peripheral venous thrombosis'.

Pain would be the only symptom that could be ascribed logically to malignant thrombosis of vessels, and it would be possible to relate pain in these patients to other mechanisms, such as obstructive pneumonitis and pleuritis, involvement of the thoracic wall, or infiltration of nerves within the tumour. A number of episodes of fairly sudden thoracic pain suggesting vascular occlusion were noted in the records. In all of these, the question of coronary occlusion was raised, but it is possible that some of these episodes may have represented vascular occlusion from either invasion of a vessel in a tumour by malignant tissue or embolism in an invaded pulmonary artery, with peripheral infarction. Peripheral infarcts were found in five cases in this series, but in only three instances were malignant thrombi present in arteries that might have been the source of emboli. Pleural effusion was also present in five cases at the time of operation; in two of these, tumour thrombi in arteries were associated with peripheral infarcts.

SuRvival Rates.- - Three of the 59 patients died in the hospital during the post-operative period, giving a hospital mortality rate of $5 \%$. Necropsy was done in two of these cases. In one metastatic lesions were found in the tracheo-bronchial lymph nodes, brain, and right adrenal. The surgical specimen in this instance showed a centrally placed, small cell carcinoma $(8 \times 6 \times 6 \mathrm{~cm}$. $)$ without involvement of lymph nodes but with a tumour thrombus in a branch of the pulmonary vein measuring $6 \mathrm{~mm}$. in diameter. In the second case, necropsy disclosed metastasis in the brain and adrenal. The surgical specimen revealed a centrally placed, small cell carcinoma $5 \mathrm{~cm}$. in diameter without demonstrable spread to lymph nodes but with involvement of a vein $4 \mathrm{~mm}$. in diameter.

Seven other patients are known to have died with either surgically proved metastasis to the central nervous system or with clinical evidence of spread in this manner.

Of the 56 patients who survived operation, 55 were traced ; 18 lived for three or more years after operation, giving a three-year survival rate of $33 \%$, exclusive of the hospital deaths. Four of the seven patients in whom evidence of invasion of blood vessels was not found survived for three or more years. Of the three who died, one patient had an operation for squamous cell carcinoma metastatic to the scapula and died subsequently, one died after a neurosurgical procedure elsewhere for what was reported to be an astrocytoma, and the third died of undetermined causes.

\section{COMMENT}

The extent and variety of metastatic lesions in bronchogenic carcinoma have been considered to result from transport of malignant emboli by the blood, and evidence is found in the present study to show that the majority of bronchogenic carcinomas have access at some time to the vascular system. Distant metastatic tumours often give rise to the chief complaint in bronchogenic carcinoma and, in the majority of instances, it appears that the cells causing these metastatic lesions are carried by the blood. Cutaneous metastatic growths (Charache, 1939 ; Furst, Scovern, and Quittner, 1949) are fairly frequent as a presenting complaint, and there have been reports of isolated secondary tumours in the terminal phalanges of digits, the mandible (Waldron, 1952), and the vaginal vestibule (Folsome, 1940). Barnard and Elliott (1930) reported two cases of intestinal obstruction caused by metastasis from bronchogenic carcinoma. Jaundice with signs of extrahepatic obstruction as the presenting findings in a case of bronchogenic carcinoma has been reported by Berkowitz, Gambescia, and Thompson (1952). 
Metastasis to the central nervous system producing either the presenting complaint or occurring during the course of the disease in bronchogenic carcinoma has been considered to be a feature of the haematogenous transport of malignant emboli. The frequency of involvement of the central nervous system has been noted by a number of authors and was well summarized in the experience of King and Ford (1942), who made necropsy examinations of the nervous system in 100 cases of bronchogenic carcinoma. Metastatic deposits were found in the central nervous system in 27 of the cases, being multiple in 20 of the 27 instances. In four cases, deposits were found in the hypothalamus, and in the anterior lobe of the hypophysis in two instances. The signs and symptoms in four of the cases were referable to the spinal cord alone.

It is possible, as emphasized by Young, Lumsden, and Stalker (1950), that sites identified in microscopic sections as probable points of entry into the blood stream are not such. They thought that tissue pressure in a tumour is the agent responsible for causing intrusion of tumour cells into blood vessels or the lymphatic system and that such procedures as the application of digital pressure or the injection of local anaesthetics that cause a local increase in tissue pressure can increase the incidence of intrusion of malignant cells into the circulation.

The association of pulmonary infarcts and bronchogenic carcinoma was reported by Hanbury, Cureton, and Simon (1954), who found peripheral infarcts in 10 of 100 cases in which pneumonectomy had been performed. They found neoplastic infiltration and thrombosis of main pulmonary arterial branches in two of these cases and compression of main vessels by tumour tissue in three, whereas the remaining five cases showed no cause for infarction.

Regardless of the mechanism involved, it appears from clinical findings and necropsy data that malignant cells of bronchogenic carcinoma gain access to blood vessels with great frequency. The lack of widespread distribution in all patients and the vagaries of sites of predilection for metastasis are puzzling. Results of animal studies designed to elucidate these points have only been partially successful. The observations of Young and his associates led them to believe that the entrance of viable cells into the blood stream and possibly the lymph stream, even though it must be an essential prerequisite to metastasis, can be nullified either by the resistance of the host or by some inherent incapacity for growth on the part of tumour cells in their new environment. Coman,
deLong, and McCutcheon (1951) studied the survival of tumour cells injected into animals and concluded that embolic tumour cells are more likely to establish themselves and form new tumours if they lodge in capillaries than if they are arrested in arterioles and that small clumps of cells (not more than two to four in a group) had a better chance for survival than did larger clumps. Pearce and Brown (1923), after extensive experience with a transplantable tumour, concluded that the dissemination of tumour cells via the blood stream does not necessarily imply the development of progressive or obvious lesions. They thought that, while the tumour cell is an essential element in metastasis, its influence is relatively constant ; they considered that the prime factors responsible for variations in the occurrence and distribution of metastatic growths are conditions that influence cellular distribution, affect the viability of the cells during transport, or affect the nutrition of the cell wherever it may become lodged.

It appears from our material that the unknown and unmeasurable factor of host resistance must play a decisive role in the survival of the patient, because the opportunity for dissemination of cells by the blood stream occurs in most cases of bronchogenic carcinoma. It is impossible to gauge what role the manipulations of the surgical procedure may play in the initiation of metastasis through vascular spread. As Aylwin has pointed out, some tumour thrombi in veins were large, and their dislodgment during operation has been responsible for sudden death. On this basis, he recommended ligation of the pulmonary veins before the tumour was manipulated. It would be difficult to do this in many instances in which the tumour is adjacent to the hilus unless the veins are tied intrapericardially. It is not possible to state whether such routine ligation of veins as an initial procedure would materially increase the long-term survival rate. Traction and manipulation of the tumour certainly should be kept to the minimum that is surgically feasible.

\section{SUMmary AND CONCLUSIONS}

A study was made at the Mayo Clinic of 59 fresh surgical specimens of bronchogenic carcinoma for evidence of invasion of blood vessels. Microscopic evidence of such invasion was discovered in 52 of these 59 specimens $(88 \%)$. Arteries had been invaded in 10 specimens.

Results of this study and of a survey of the literature warrant the following conclusions:

The incidence of microscopic invasion of blood vessels in surgically resected specimens of broncho- 
genic carcinoma is great. Invasion of pulmonary arteries and their branches is common. But angiocardiographic evidence of arterial invasion need not be considered evidence for inoperability unless occlusion approaches the bifurcation of the pulmonary trunk, so that ligation would not be feasible.

Invasion of pulmonary arteries by bronchogenic carcinoma may be a factor in the production of peripheral infarcts and perhaps occasionally of peripheral spread in a "lymphogenous" pattern. Peripheral infarcts may be associated with pleural effusion, which should not always be considered a sign of inoperability. Peripheral infarction or thrombosis in pulmonary vessels invaded by bronchogenic carcinoma may give rise to symptoms simulating acute coronary disease.

The ready access of malignant cells to the systemic circulation explains the high incidence of the widespread and sometimes bizarre distribution of the distant metastatic tumours in bronchogenic carcinoma.

Microscopic evidence of invasion of blood vessels in bronchogenic carcinoma does not necessarily indicate short-term survival.

It is difficult to assess the possible role of the surgeon in disseminating tumour emboli as a consequence of manipulation during operation. Dislodgment of large fragments of tumour in pul- monary veins as a cause of sudden death should be recognized as an occasional possibility. Minimal manipulation should be practised and preliminary ligation of veins should be considered in an effort to increase survival rates.

The resistance of the host may be of prime importance in determining the fate of malignant cells that gain access to the blood stream.

\section{REFERENCES}

Adler, I. (1912). Primary Malignant Growths of the Lungs and Bronchi. Longmans, Green, and Company, New York.

Aylwin, J. A. (1951). Thorax, 6, 250.

Barnard, W. G., and Elliott, T. R. (1930), Ouart. J. Med., 23, 407. Berkowitz, D., Gambescia, J. M., and Thompson, C. M. (1952) Gastroenterology, 20, 653 .

Charache, H. (1939). Amer. J. Cancer, 37, 431.

Coman, D. R., deLong, R. P., and McCutcheon, M. (1951). Cancer Res., 11, 648.

Dotter, C. T., Steinberg, I., and Holman, C. W. (1950). Amer. J. Roentgenol., 64, 222.

Folsome, C. E. (1940). J. Amer. med. Ass., 114, 1499.

Fried, B. M. (1927). Arch. intern. Med., 40, 340.

Furst, N. J., Scovern, L., and Quittner, H.(1949). J. med. Soc., N.J., 46, 387.

Grove, J. S., and Kramer, S. E. (1926). Amer. J. med. Sci., 171, 250 Hanbury, W. J., Cureton, R. J. R., and Simon, G. (1954). Thorax,

Keil, P. G., Voelker, C. A., and Schissel, D. J. (1950). Amer. J. med. Sci., 219, 301.

King, A. B., and Ford, F. R. (1942). Bull. Johns Hopk. Hosp. .70, 124 Pearce, L., and Brown, W. H. (1923). J. exp. Med., 38, 347.

Simons. E. J. (1937). Primary Carcinoma of the Lung. Year Book Publishers, Chicago.

Simpson, S. L. (1929). Ouart. J. Med., 22, 413.

Simpson, S. L. (1929). Quart. J. Med., 22, 413. 194$)$. Thorax, 9, 91.

Slesser, B. V., Britt, R. G., and Freer, J. L.

Waldron, C. A. (1952). Oral Surg., 5, 185. Orch. Path. (Chicago), 7, 478.

Wiklund, T. (1951). Acta chir. scand., Suppl., 162.

Young, J. S. Lumsden, C. E., and Stalker, A. L. (1950). J. Path. Bact., 62, 313. 